for liquids, they can be adequately coated internally to render them leak-proof. So far, plywood containers have been made at Dehra Dun for paints, oils, greases, dry goods, foodstuffs, medical stores and water. In addition, they have been kept filled with kerosene and petrol for several months without showing any signs of evaporation or leakage. A variety of inner coatings have been tested.

The leaflet is chiefly concerned with a description of the methods of manufacturing plywood drums, a detailed description with diagrams being given. The glue used for container work is a casein cement which can be prepared according to a formula of the Forest Products Laboratories, Madison, U.S.A.; this is recommended by the Dehra Dun Institute and is given in the leaflet.

Owing to the fact that the round containers take up much space in storage and transit, a rectangular plywood container has been designed by the Forest Research Institute. This is described in Leaflet No. 26, "Rectangular Plywood Containers" (Dehra Dun, 1942). The four sides are made of ordinary commercial 3-plywood. These are joined together by bent plywood corner pieces, rivets being used for fastening the corner pieces to the side sheets. Top and bottom are of 7-plywood and are fixed in the same way as the round wood container described in leaflet No. 24. Full details with diagrams are given.

\section{SOME BRITISH EMPIRE TIMBERS}

U NDER the auspices of the Department of Scientific and Industrial Research, the Forest Products Research Laboratory has issued a War Emergency Supplement to the "Handbook of Empire Timbers" published in 1939, edited by Mr. H. A. Cox (London: H.M. Stationery Office, 1943). In Part 1 some additional information on many of the timbers already dealt with is given, especially in connexion with insect attacks, though in the case of teak the data given have been known for many years.

In Part 2 sixteen species not previously described are dealt with under the heads of brief description of tree, its timber, seasoning properties, wood bending and mechanical properties, natural durability, insect attack, preservative treatment, working qualities, uses and supplies - the last-named a most important piece of information in the absence of which the rest has, from a commercial point of view, little more than an academic value. Some of the West African timbers in this list are of interest since the French were exporting them to Western Europe before the French Colonial Exposition held in Paris in 1931. The information given here on some of these species on this head is too qualified and guarded to be of much practical use.

The following hardwoods are dealt with : Mitragyna stipulosa, equatorial forests of Nigeria, Liberia, Ivory Coast, Cameroons and Gamboon, most frequently in association with Sarcocephalus diderrichii; Piptadenia africana, rain and mixed deciduous forests of Nigeria ; also in Gold Coast, Ivory Coast, Cameroons, Belgian Congo and Angola; Betula papyrifera, moist slopes in eastern North America from the southern shores of Hudson's Bay to Labrador in the north to approximately $40^{\circ} \mathrm{N}$. in the south; Canarium schweinfurthii, Sierra Leone to East Africa ;
Celtis soyauxii, West Africa, Central Africa, Uganda, Tanganyika and parts of Kenya; Acer rubrum and $A$. saccharinum (soft maples), eastern Canada, $A$. rubrum extending to Newfoundland. A. macrophyllum, the Pacific maple; Terminalia amazonia (Nargusta), Central American rain-forest region including British Honduras and Trinidad; purpleheart-various species of Peltogyne, Trinidad, British and French Guiana and Surinam-probably a wider distribution the limits of which are not definitely known; Beilschmiedia tawa (Tawa), lowland and mountain forests in North Island and to a very limited extent in the northern part of South Island, New Zealand.

The softwoods are limited to Abies grandis, Vancouver Island and on mainland opposite, extending southward into the United States as far as California; Tsuga canadensis (eastern hemlock), lower basin of St. Lawrence and Nova Scotia, with much more extended range in the United States; Pinus ponderosa, with its varieties extending from California, New Mexico and Western Texas in the south to southern British California in the north; Picea engelmannii from Alaska to New Mexico, attaining its greatest size in British Columbia ; Larix laricina (tamarack) and Larix occidentalis (western larch), upper basin of Columbian river in British Columbia stretching southwards into United States as far as Oregon and Montana; Podocarpus totara and $P$. Lallii (totara), lowland and mountain forests in North and South Islands of New Zealand, and $P$. Lallii also in Stewart Island.

Some kiln schedules for a number of species are given in a series of appendixes. It is emphasized that these schedules are approximate only and represent conditions suitable for average qualities of timber intended for normal use. It is added that experience with timber from particular sources of supply destined for specific purposes will generally enable modifications to be made.

\section{COASTAL RADIO TELEPHONE}

$\mathrm{N}$ an article with this title (Bell Lab. Rec., 21, No. 7 ; March 1943), H. M. Pruden describes the present status of the radio telephone service between shore and vessels off the coast of the United States or within its harbours, which has undergone considerable growth and development during the past decade. The development work leading to the present successful system was begun more than twenty years ago, and as a result of this a complete coastal radio system is now in use. It consists of fourteen basic shore stations so located as to cover the entire coast from Maine, through the Gulf of Mexico, and up the Pacific coast to Seattle.

Each of the shore stations includes a radio trans. mitter, two or more radio receivers, and terminal equipment for associating each with the other and with their signalling and control circuits. The terminal equipment is installed in the toll office, and the transmitter is installed in a small building erected for the purpose or in a telephone building or leased property. 'The receivers, however, are usually at some distance from the transmitters and are generally mounted on poles. Since the transmitting equipment aboard ship is not so powerful as that on shore, the shore receivers are spaced at shorter intervals than are the transmitters. In general, the receivers 
are so placed that any ship that can be reached satisfactorily by a shore station can in turn be picked up satisfactorily by one of the receivers associated with that shore transmitter.

Transmission from the shore station is at a frequency within the band 2,504-2,600 kc., while the shore receivers operate at between 2,108 and 2,208 kc. To call a shore station, the desired frequency is selected, the headset aboard ship is lifted, and the 'talk' switch on the handle is pressed. This turns on the ship's transmitter, and the radiated carrier causes a carrier-operated relay in one or more of the shore receivers to operate and light a lamp in front of an operator.

Two methods are available for calling ships. The more completely equipped vessels have a selective signalling system. The operator dials the ship as he would any shore subscriber, and a bell is rung aboard the vessel called. For ships not equipped for dial calling, the operator transmits a 1,000-cycle tone over the carrier from the shore transmitter, and then calls the ship by name or by its call letters. Such vessels have a loudspeaker associated with their radio receiver, and the tone serves as an attention signal. Besides completing calls between ship and shore, the terminal facilities also permit radio telephone conversations between ships through a shore station. The operating procedure is for the ship to call shore and ask for a connexion to some other ship. The shore operator then calls this other ship, and having reached it, plugs into a by-pass jack, which, through suitable contacts, rearranges the circuit. The output of the radio receiver is, connected to the input of the transmitter through a network, so that speech is re-transmitted at a frequency that can be detected by either vessel.

One of the innovations in the new terminal equipment is the ability to make contact with the emergency radio equipment of the telephone companies. This emergency equipment is designed to take the place of wire facilities that are temporarily out of service. The ability of the shore stations to communicate with these emergency sets is very helpful at times in establishing the original connexion, since then only one of the emergency sets is required, the shore station taking the place of the other. A second emergency equipment is put into use as soon as possible, however, and the operating frequency changed, so as not to tie up harbour equipment. The shore station radiates carrier continuously while handling calls with vessels, while for the emergency equipment the carrier must be under voice control. To make this possible, the technical operator is provided with a key that rearranges the circuit. The switching relay operates under control of the incoming carrier, to connect the shore circuit to the radio-receiver. Under these conditions, there is no speed input to the vogad and hence none to the amplifier-detector. As a result there is no current through the winding of the voice-holdover relay, and a circuit through its back contact disables the radio transmitter. When incoming speech ceases, the switching relay is released, thus connecting the shore circuit to the transmitter. Voice signals from the shore circuit result in a current in the output of the amplifier-detector that operates the voice-holdover relay, and causes the transmitter to radiate carrier. The same current also operates the echo-holdover relay, thus opening the circuit to the switching relay so that incoming speech cannot interfere with outgoing signals.

\section{CLIMATE AND ANIMAL DISEASE IN INDIA}

T $\mathrm{N}$ his presidential address read before the Section of Medical and Veterinary Sciences of the thirtieth Indian Science Congress held at Calcutta last January, Dr. F. C. Minett, director of the Imperial Veterinary Research Institute, Muktesar, United Provinces, discussed the influence of climate on the incidence of disease.

At the outset, Dr. Minett emphasized the value of the association of medical men and veterinarians in research, as is exemplified in the Indian Science Congress and in the Section of Comparative Medicine of the Royal Society of Medicine. While admitting that veterinary science has gained more than it has given by contact with medicine, he dwelt on the enormous extent to which medical science has had to rely upon experiments on animals in connexion with elucidation and prevention. As regards the effect of climate and weather conditions on animal health and disease, Dr. Minett mentioned the influence of air temperature and humidity on the spread of such diseases as filariasis, malaria and plague. On the other hand, climate may not be the only environmental factor at work; other complex influences, such as naturally acquired immunity and conditions of crowding, may be still more important. Climatic factors might be neutralized by the occurrence of improved facilities for disinfection, as in the case of cholera. As the relation between weather effects and disease in man cannot always be determined by statistics, experiments on animals are needed, with results which may or may not confirm previous deductions.

Although a good deal is known of the effect of environmental factors, including climate, on human beings and small experimental animals, comparatively little is known with regard to domesticated animals like sheep and goats. In order to obtain more exact information, figures are being collected through provincial directors of veterinary services relating to the prevention of animal diseases during the monsoon period, just as has been done on the medical side with cholera, typhoid, etc. As regards the monsoon prevalence of disease, wet conditions are a sore trial to many animals in some tropical countries, even to such water-loving animals as buffaloes. The effect of rainfall on animals has recently been studied by artificial showers. Sheep inoculated intramuscularly with very small doses of spores of $\mathrm{Cl}$. chauvoei, the causal agent of blackwater in cattle and sheep, showed symptoms of the disease and died after exposure to a shower, while control sheep remained healthy. On the other hand, guinea pigs injected with the spores and then treated in an incubator at $40^{\circ} \mathrm{C}$. are more likely to escape the disease than controls. A similar effect has been produced in the case of anthrax.

Dr. Minett next dealt with the deterioration or degeneration of cattle, which it is hoped will be investigated by the Imperial Council of Agricultura] Research. Whether the deterioration is solely or mainly due to climate is not yet known; but if it is, it will have to be determined whether climate is exerting a direct effect on the animal physiology, or whether the effect is indirect and is more properly to be attributed to a hot atmosphere.

In conclusion, Dr. Minett referred to the control of disease in India, which is hindered by religious 